\title{
HEPATIC BIOTRANSFORMATION PROFILES OF SULPHAMONOMETHOXINE IN FOOD-PRODUCING ANIMALS AND RATS IN VITRO
}

\author{
N. FURUSAWA* \\ Faculty of Human Life Science, Osaka City University, Osaka 558-8585, Japan
}

(Received January 3, 2000; accepted May 3, 2000)

\begin{abstract}
Hydroxylation and acetylation of sulphamonomethoxine (SMM) and deacetylation of $\mathrm{N}^{4}$-acetyl SMM $\left(\mathrm{N}^{4}\right.$-AcSMM) were estimated in liver postmitochondrial supernatants (S-9) from laying hens, female cattle, swine and rats. The formation of hydroxylated SMM, 2,6-dihydroxy SMM (2,6-diOH-SMM), was found only with hen S-9s. $\mathrm{N}^{4}$-acetylation rate of SMM was the highest in pig S-9s, followed by rat, then hen or cow S-9s. All S-9s from the four species deacetylated $\mathrm{N}^{4}$-AcSMM. In hen $\mathrm{S}-9 \mathrm{~s}$, the rate of 2,6-dihydroxylation was higher during incubation at $41^{\circ} \mathrm{C}$ than at $37^{\circ} \mathrm{C}$.
\end{abstract} lation

Key words: Sulphamonomethoxine, hydroxylation, acetylation, deacety-

Sulphamonomethoxine (4-sulphanilamido-6-methoxy-pyrimidine, SMM) is one of the antibacterial drugs most commonly used for the treatment or prevention of diseases of food-producing animals in Japan. Considerable in vivo studies on SMM metabolism in laying hens (Furusawa, 1999), pigs (Shimoda et al., 1984; Shimoda et al., 1988), cows, rats (Vree et al., 1985a), snails (Vree et al., 1989b), turtles (Vree et al., 1989a) and humans (Vree et al., 1990) have demonstrated that species-dependent SMM metabolism is either qualitative (differing metabolic pathways) or quantitative (differing rates but same metabolic pathway). $\mathrm{N}^{4}$-acetyled SMM ( $\mathrm{N}^{4}$-AcSMM) was determined in the urine of all the species, but the percentage of $\mathrm{N}^{4}$-AcSMM to excretory compounds in urine differed among species. $\mathrm{N}^{1}$-glucuronidation reaction takes place in humans (Vree et al., 1990) but is negligible in other species. In turtles, SMM hydroxylation occurs at the 2-position, 6-position or both the 2- and 6-positions of the pyrimidine ring (Vree et al., 1989a) (Fig. 1). Snails are able to hydroxylate SMM at the 2position only (Vree et al., 1989b).

$\mathrm{N}^{4}$-AcSMM possesses the following chemical and pharmacological properties: (1) it has lower solubility ( $\mathrm{pH} 7.0)$ and higher plasma protein binding than that of SMM in vitro (Vree and Hekster, 1987), which may affect its excretion

*E-mail: furusawa@life.osaka-cu.ac.jp; Fax: ++81-6-6605-2864 
rate; (2) it is deacetylated to the parent compound in vivo (Shimoda et al., 1988). It has been found that acetyl metabolites and glucuronides of sulphonamides have no antibacterial activities, but their hydroxy metabolites do (Nouws et al., 1985; Nakata and Fukuda, 1994). Thus, the ability/pathway to metabolize SMM may be of prime importance in determining the residues of hydroxyl- and/or $\mathrm{N}^{4}$ acetyl metabolites in foods derived from the treated animals as well as the efficacy, duration of action and toxicity of the target drug.

$N^{4}$-ACSMM:

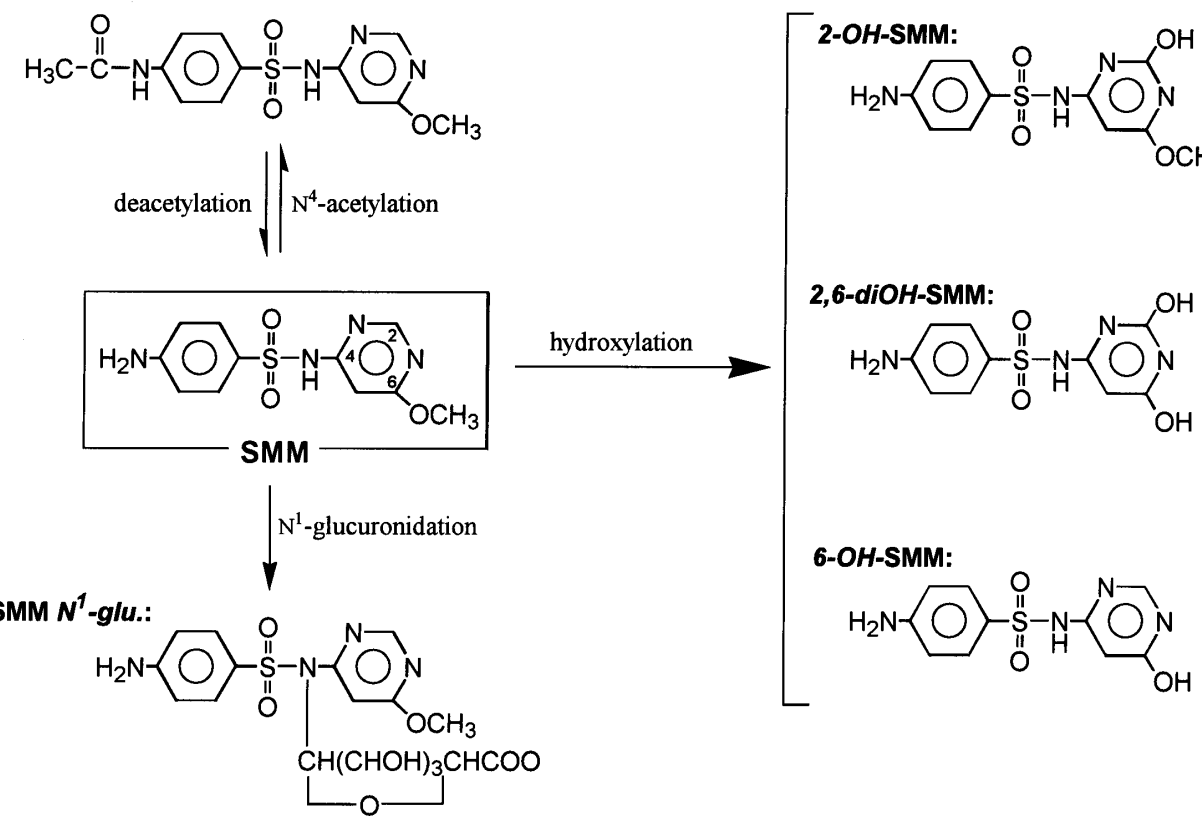

Fig. 1. Structural formulas of sulphamonomethoxine (SMM) and its possible metabolites

In contrast to in vivo experiments on target drugs which require many test animals, in vitro experiments are a convenient model for examining drug metabolism, require the use of fewer animals and less time for experiments, and are more economical.

This paper presents the in vitro hepatic biotransformation profiles of SMM in food-producing animals (hens, cattle and swine) and rats. To perform the collective study of first- and second-phase SMM metabolism, the experiment used the post-mitochondrial supernatant containing the microsomal (= hydroxylation, $\mathrm{N}^{1}$-glucuronidation and deacetylation) plus soluble (cell sap) $\left(=\mathrm{N}^{4}\right.$-acetylation) fractions of the cell (Gibson and Skett, 1994a). 


\section{Materials and methods}

Drugs and animals. SMM standards were obtained from Sigma (St. Louis, MO, USA). Possible hydroxy metabolites of SMM, i.e. $\mathrm{N}^{1}$-(6-methyl-2-hydroxy4-pyrimidinyl) sulphanilamide (2-OH-SMM), $\mathrm{N}^{1}$-(6-hydroxy-4-pyrimidinyl) sulphanilamide (6-OH-SMM), $\mathrm{N}^{1}$-(2,6-dihydroxy-4-pyrimidinyl) sulphanilamide (2,6-diOH-SMM), and $\mathrm{N}^{4}$-acetyl SMM ( $\mathrm{N}^{4}$-AcSMM) (Fig. 1) were a generous gift from Dr. Miura (Daiichi Seiyaku, Tokyo, Japan).

Six laying Brown Leghorn hens (aged 17 months) and six Wistar rats (aged 8 weeks, female, Clea Japan, Inc., Osaka), given a drug-free basal diet and tap water ad libitum, were slaughtered and the livers were collected. Livers of five healthy cows (aged 12 months) and five pigs (aged 6 months, female) were purchased from Osaka City Meat Inspection Office (Osaka, Japan). These animals had not been treated with drugs for at least one month prior to slaughtering.

Experimental design. The liver tissues were prepared as follows. All equipment, solutions and the liver tissues were kept at a temperature not exceeding $4{ }^{\circ} \mathrm{C}$ during any stage of preparation and isolation. A $25 \%(\mathrm{w} / \mathrm{v})$ homogenate was made in $0.1 \mathrm{M}$ phosphate buffer ( $\mathrm{pH}$ 7.3) using a glass Potter-type homogenizer with a Teflon pestle (Teflon ${ }^{\circledR}$ Homogenizer, Masuda Co., Osaka, Japan). To prepare the post-mitochondrial supernatant (S-9), the homogenate was centrifuged at $4{ }^{\circ} \mathrm{C}$ at $9000 \mathrm{~g}$ for $15 \mathrm{~min}$ in a refrigerated centrifuge. The resulting supernatant, S- 9 , was reserved and stored at $-80{ }^{\circ} \mathrm{C}$ until use. The use of liver S-9s to study biotransformation is a simple method, the major advantage of which is its simplicity.

Total protein level was determined by the use of a commercial kit (A/G Btest Wako ${ }^{\circledR}$, Wako Pure Chem., Ltd., Osaka, Japan) as the standard protein of bovine serum origin, according to the 'biuret method' using copper sulphate pentahydrate $\left(\mathrm{CuSO}_{4} \times 5 \mathrm{H}_{2} \mathrm{O}\right)$.

The biotransformation of S-9s was assayed in conformity with a procedure described previously (Gibson and Skett, 1994b). That is, S-9s were incubated with SMM (3 mmol) in an incubation mixture $(0.1 \mathrm{M}$ phosphate buffer, $\mathrm{pH} 7.4)$ containing an NADPH-generating system $\left(\mathrm{NADP}^{+}, 0.45 \mu \mathrm{mol}\right.$; glucose-6-phosphate, $20.0 \mu \mathrm{mol} ; \mathrm{MgCl}_{2} \times 6 \mathrm{H}_{2} \mathrm{O}, 50 \mu \mathrm{mol}$; nicotinamide, $\left.7.5 \mu \mathrm{mol}\right)$ at $37^{\circ} \mathrm{C}$ or $41^{\circ} \mathrm{C}$ for $1 \mathrm{~h}$, in triplicate. After $1 \mathrm{~h}$, the mixture sample was placed in a boiling bath for $10 \mathrm{~min}$ to terminate the enzyme reaction. The blank sample incubations should be prepared as above, but by substituting a tissue homogenate previously heated to $80-100{ }^{\circ} \mathrm{C}$ for $10 \mathrm{~min}$ to denature the enzymes. Moreover, the suitable blank was prepared by replacing SMM with $0.1 \mathrm{M}$ phosphate buffer ( $\mathrm{pH}$ 7.4).

For deacetylation of $\mathrm{N}^{4}-\mathrm{AcSMM}$ in $\mathrm{S}-9 \mathrm{~s}$, the experiment using $\mathrm{N}^{4}$ AcSMM ( $3 \mathrm{mmol})$ was conducted in the same manner as above.

The cow, pig and rat samples were incubated at $37^{\circ} \mathrm{C}$. Since the body temperature of laying hens $\left(41^{\circ} \mathrm{C}\right)$ (Fujiwara and Horiuchi, 1990) is higher than 
those of other species $\left(37-38{ }^{\circ} \mathrm{C}\right)$, the hen samples were incubated at both $41{ }^{\circ} \mathrm{C}$ and $37^{\circ} \mathrm{C}$. The effect of incubation temperature differences on biotransformation in hens was examined.

Deglucuronidation: in accordance with a procedure described previously (Shimoda et al., 1990), deglucuronidation of the samples was performed with $\beta$ glucuronidase (E. coli, 10,000 U/ml; Sigma) in $0.2 \mathrm{M}$ phosphate buffer (pH 6.8) or $\beta$-glucuronidase (type B1, 10,000 U/ml; Sigma) in $0.2 \mathrm{M}$ phosphate buffer (pH 5.0). The mixtures were allowed to reach $6 \mathrm{~h}$ at $37^{\circ} \mathrm{C}$.

Analysis: a $0.2 \mathrm{ml}$ of the mixture sample was put into Ultrafree ${ }^{\mathrm{TM}}$ (C3 LBC, disposable ultra-filtration unit, Millipore, Milford, MA, USA) and centrifuged at $5000 \mathrm{~g}$ for $10 \mathrm{~min}$. The filtrate was analyzed by high-performance liquid chromatography (HPLC) under the following conditions: mobile phase, 4\% (v/v) acetic acid solution-acetonitrile-N,N-dimethylformamide $(86: 10: 4, \mathrm{v} / \mathrm{v} / \mathrm{v})$; flow rate, $1.0 \mathrm{ml} / \mathrm{min}$; detection, $270 \mathrm{~nm}$ (a photo-diode array detector). The column was a Mightysil ${ }^{\circledR}$ RP-4 GP $(5 \mu \mathrm{m})$ column $(4.6 \times 250 \mathrm{~mm})$ (Kanto Chem. Co., Inc., Tokyo, Japan) with a guard column $(4.6 \times 5 \mathrm{~mm})$ (Kanto Chem.). The limits of detection in the resulting incubation S-9 samples were $0.17 \mu \mathrm{mol}$ for hydroxylated SMMs, $0.16 \mu \mathrm{mol}$ for SMM and $0.15 \mu \mathrm{mol}$ for $\mathrm{N}^{4}$-AcSMM, respectively.

Statistical analysis: for SMM hydroxylation or $\mathrm{N}^{4}$-acetylation rates and $\mathrm{N}^{4}$-AcSMM deacetylation rates in the hen, cow, pig and rat S-9s, the significance of differences between means was examined by Studentized Tukey's test with one-way analysis of variance. The analysis was accomplished using $\mathrm{SAS}^{\circledR}$ software (SAS Institute, 1994).

\section{Results}

Figure 2 shows examples of typical HPLC traces of blanks and incubated hen samples. The resulting extracts were free from interference (Fig. 2A and B). For blank samples, similar chromatograms were obtained from cow, pig and rat samples. As for metabolites of SMM in hen S-9s, 2,6-diOH-SMM and $\mathrm{N}^{4}$ AcSMM were detected (Fig. 2). In cow, pig and rat S-9s, $\mathrm{N}^{4}-\mathrm{AcSMM}$ was the only detectable metabolite.

The biotransformation rates are summarized in Table 1. The acetylation of SMM occurred at the highest rate in pig S-9, followed by rat, cow and hen S-9s. There is no significant difference between hen S-9 and cow S-9. The 2,6dihydroxylation of SMM, 2,6-diOH-SMM, occurred only with hen S-9s.

Deacetylation of $\mathrm{N}^{4}$-AcSMM was determined in S-9s from all four species. Deacetylation rates were highest in pig $(\mathrm{P}<0.01)$ and lowest in rat $(\mathrm{P}<0.01)$ (Table 1). In hen S-9, the effect of difference in incubation temperature on 2,6-dihydroxylation was significant $(\mathrm{P}<0.01)$, while that on $\mathrm{N}^{4}$ acetylation and deacetylation of $\mathrm{N}^{4}$-AcSMM was insignificant $(\mathrm{P}>0.05)$. 


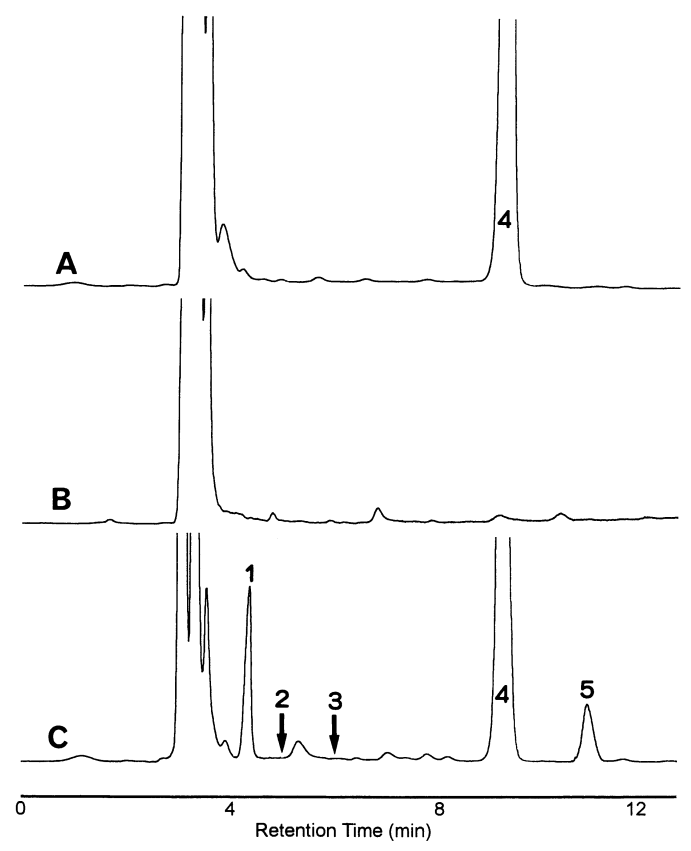

Fig. 2. HPLC chromatograms. A: substituting blank hen S-9 sample (see text); B: suitable blank hen S-9 sample; C: hen S-9 sample. For HPLC conditions see text. Peaks: 1 = 2,6-diOH-SMM; $2=2-\mathrm{OH}-\mathrm{SMM} ; 3=6-\mathrm{OH}-\mathrm{SMM} ; 4=\mathrm{SMM} ; 5=\mathrm{N}^{4}$-AcSMM. No 2-OH-SMM and 6-OH-SMM were detected

Table 1

Biotransformation rates of SMM and $\mathrm{N}^{4}-\mathrm{AcSMM}$ in S-9s from hens, cows, female pigs and rats

\begin{tabular}{lcccc}
\hline Species & $\begin{array}{c}\text { Incubation } \\
\text { temperature }\left({ }^{\circ} \mathrm{C}\right)\end{array}$ & $\begin{array}{c}\text { Hydroxylation }^{\#} \\
(2,6 \text {-diOH-SMM) }\end{array}$ & $\begin{array}{c}\mathrm{N}^{4} \text {-acetylation } \\
\left(\mathrm{N}^{4} \text {-AcSMM }\right)\end{array}$ & $\begin{array}{c}\text { Deacetylation } \\
(\mathrm{SMM})\end{array}$ \\
\hline Hens & 41 & $6.40 \pm 0.54^{\mathrm{a}}$ & $0.69 \pm 0.17^{\mathrm{c}}$ & $0.25 \pm 0.02^{\mathrm{b}^{*}}$ \\
& 37 & $2.31 \pm 0.26^{\mathrm{b}}$ & $0.65 \pm 0.14^{\mathrm{c}}$ & $0.24 \pm 0.02^{\mathrm{b}^{*}}$ \\
Cows & 37 & nd & $0.67 \pm 0.16^{\mathrm{c}}$ & $0.28 \pm 0.03^{\mathrm{b}^{*}}$ \\
Pigs & 37 & nd & $26.33 \pm 0.94^{\mathrm{a}}$ & $2.68 \pm 0.29^{\mathrm{a}^{*}}$ \\
Rats & 37 & nd & $4.58 \pm 1.46^{\mathrm{b}}$ & $0.13 \pm 0.03^{\mathrm{c}^{*}}$ \\
\hline
\end{tabular}

${ }^{\#}$ Data are expressed as mean formation rates $(\mu \mathrm{mol} / \mathrm{mg}$ protein $/ \mathrm{h}) \pm$ standard error $(\mathrm{SE}, \mathrm{n}=6)$ of 2,6-diOH-SMM and $\mathrm{N}^{4}$-AcSMM; Data are expressed as mean formation rates ( $\mu \mathrm{mol} / \mathrm{mg}$ protein $/ \mathrm{h}) \pm \mathrm{SE}(\mathrm{n}=6)$ from $\mathrm{N}^{4}$-AcSMM to SMM; Means with different superscripts $\left({ }^{\mathrm{a}, \mathrm{b}, \mathrm{c}, \mathrm{d}}\right)$ in the same column differ significantly $(\mathrm{P}<0.01$ among $\mathrm{a}, \mathrm{b}$ and $\mathrm{c} ; \mathrm{P}<0.05$ between $\mathrm{c}$ and $\mathrm{d})$; ${ }^{*}$ Significantly different from the left value $\left(\mathrm{N}^{4}\right.$-acetylation $)(\mathrm{P}<0.01)$ in the same row; nd: No 2,6diOH-SMM was detected 


\section{Discussion}

No increase of SMM peak by deglucuronidation treatment was detected in any of the incubated samples, suggesting a lack of SMM N ${ }^{1}$-glu. (Fig. 2). Consequently, no SMM metabolites other than 2,6-diOH-SMM and $\mathrm{N}^{4}$-AcSMM, like 2-OH-, 6-OH-SMMs and related conjugated compounds including SMM N ${ }^{1}$-glu., were detected in the present study.

As for in vivo chicken studies, Takahashi (1986a, $b$ ) reported on 6-hydroxylated sulphadimethoxine (SDM) in chickens (White Leghorn). Eighty percent of the intravenous dose $\left(10 \mathrm{mg} / \mathrm{kg}\right.$ b.w.) was excreted as SDM, $\mathrm{N}^{4}$-acetyl SDM and 6-hydroxylated SDM (6-OH-SDM), with the major portion (43\%) being 6OH-SDM (SDM, 20\%; N ${ }^{4}$-AcSDM, 17\%). Similar findings have been reported in relation to sulphadimidine (SDD) (Nouws et al., 1986). Sixteen percent of the dose was excreted as hydroxyl SDD. $\mathrm{N}^{4}$-AcSDD and SDD accounted for $12.7 \%$ and $13.9 \%$ of the dose, respectively, while no glucuronides were found. Additionally, SMM and SDM produce the same metabolites, 2-OH-SMM $(=2,6-$ diOH-SDM) and 2,6-diOH-SMM (= 2,6-diOH-SDM), 2-, and 6-hydroxylations (Vree et al., 1989a; Vree et al., 1989b; Vree et al., 1989c) (Figs 1, 3). The results obtained in this study support the above findings (Table 1). Thus, hydroxylation plays a principal role in the biotransformation of sulphonamides in chickens.

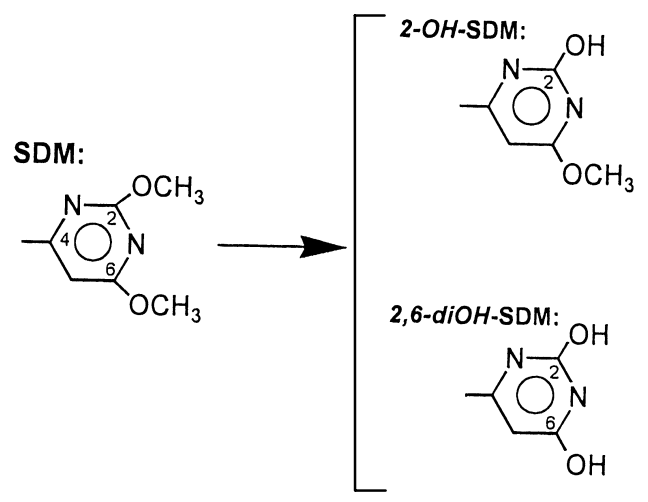

Fig. 3. Structural formulas of pyrimidine rings in hydroxy metabolites of sulphadimethoxine (SDM). Both hydroxy metabolites are common with those of SMM shown in Fig. 1

During incubation at $41{ }^{\circ} \mathrm{C}$ (i.e. at the body temperature of hens), 2,6dihydroxylation, a biotransformation characteristic of SMM in hens, was 2.7 times higher in hen S-9 than at $37^{\circ} \mathrm{C}$ (Table 1). This new finding is of particular interest in relation to in vitro drug metabolism studies in chickens.

In vivo studies on the excretion of SMM in pigs, cows and rats, but excluding chickens, have been reviewed. Shimoda et al. (1984) reported that SMM 
in pigs were highly $\mathrm{N}^{4}$-acetylated, and that $80 \%$ of the dose excreted in the urine was $\mathrm{N}^{4}$-AcSMM. Similarly, in cows and rats, $\mathrm{N}^{4}$-AcSMM was one of the metabolites of SMM excreted in the urine. The percentage of $\mathrm{N}^{4}$-AcSMM to total excretory products in the urine was $12 \%$ in cows and $54 \%$ in rats (Vree et al., $1985 b$ ). Thus, the sole metabolite of SMM that could be detected in their urine was $\mathrm{N}^{4}$-AcSMM. The ranking of the three species with respect to the percentage of $\mathrm{N}^{4}$-AcSMM to total excretory compounds was pig $>$ rat $>$ cow. The in vivo findings correspond well with the in vitro data shown in Table 1.

The SMM acetylation rate was higher than the deacetylation rate for all the species. In previous in vivo studies, an acetylation - deacetylation equilibrium of sulphonamides in animals has been demonstrated (Vree et al., 1985a; Vree et al., 1985b). Furusawa (1999) has demonstrated an equilibrium in the depletion of SMM and $\mathrm{N}^{4}$-AcSMM in blood and various tissues of laying hens in vivo, i.e. the elimination half-lives of SMM and $\mathrm{N}^{4}-\mathrm{AcSMM}$ were equal. A similar observation has been reported for the plasma of pigs (Shimoda et al., 1988). Therefore, it may be stated that the presence of $\mathrm{N}^{4}$-AcSMM in the excreta of hens or in the urine of pigs results from a complex equilibrium of acetylationdeacetylation formations and SMM- ${ }^{4}$-AcSMM elimination.

In conclusion, the present study shows that (1) the use of S-9s from target animals for in vitro hepatic biotransformation studies of SMM may be helpful for mapping the biotransformation/excretion patterns and toxicological activities of SMM in food-producing animals, and requires the use of fewer live test subjects; (2) the main pathway of in vitro hepatic biotransformation of SMM in laying hens was 2,6-dihydroxylation (2,6-diOH-SMM), which is a pharmacokinetic characteristic of the hen because such formation was not found in cows, pigs and rats; and (3) processing of the reaction at $41{ }^{\circ} \mathrm{C}$ for hens may provide a nearer approximation to in vivo situations.

\section{References}

Gibson, G. G. and Skett, P. (1994a): Pathways of drug metabolism. In: Gibson, G. G. and Skett, P. (eds) Introduction to Drug Metabolism. 2nd edition. Chapman \& Hall Press, London. pp. $1-37$.

Gibson, G. G. and Skett, P. (1994b): Techniques and experiments illustrating drug metabolism. In: Gibson, G. G. and Skett, P. (eds) Introduction to Drug Metabolism. 2nd edition. Chapman \& Hall Press, London. pp. 217-256.

Fujiwara, K. and Horiuchi, S. (1990): Chicken. In: Fujiwara, K. and Horiuchi, S. (eds) Experimental Animals for Toxicity Tests. Chijin Syokan, Tokyo. pp. 101-110.

Furusawa, N. (1999): Depletion rate of $\mathrm{N}^{4}$-acetylsulphamonomethoxine in tissues of laying hens. Vet. J. 157, 103-105.

Nakata, T. and Fukuda, Y. (1994): Distribution and elimination of sulphamonomethoxine and its metabolites in treated chicken. J. Pharm. Pharmacol. 46, 1004-1012.

Nouws, J. F. M., Vree, T. B. and Hekster, Y. A. (1985): In vitro antimicrobial activity of hydroxy and $\mathrm{N}_{4}$-acetyl sulphonamide metabolites. Vet. Quart. 7, 70-72. 
Nouws, J. F. M., Vree, T. B., Aerts, R. and Grondel, J. (1986): Pharmacokinetics and residues of sulfadimidine, its $\mathrm{N}_{4}$-acetyl and hydroxy metabolites in food producing animals. Arch. Lebensmittelhyg. 37, 57-84.

SAS Institute (1994): SAS ${ }^{\circledR}$ User's Guide (Cary, NC).

Shimoda, M., Kokue, E., Shimizu, T., Muraoka, R. and Hayama, T. (1988): Role of deacetylation in the nonlinear pharmacokinetics of sulfamonomethoxine in pigs. J. Pharmacobio-Dynamics 11, 576-582.

Shimoda, M., Shimizu, T., Kokue, E. and Hayama, T. (1984): Possibility of saturation in renal excretion after high dose of intravenous sulfamonomethoxine in pigs. Jpn. J. Vet. Sci. 46, 331-337.

Shimoda, M., Vree, T. B., Kolmer, E. W. J. B. and Arts, Th. H. M. (1990): The role of plasma protein binding on the metabolism and renal excretion of sulphadimethoxine and its metabolite $\mathrm{N}^{4}$-acetylsulphadimethoxine in pigs. Vet. Quart. 12, 87-97.

Takahashi, Y. (1986a): Mechanisms of nonlinear pharmacokinetics of sulfadimethoxine in cocks. Jpn. J. Vet. Sci. 48, 105-109.

Takahashi, Y. (1986b): Identification of desmethyl metabolite of sulfadimethoxine in chicken excreta. Jpn. J. Vet. Sci. 48, 999-1002.

Vree, T. B. and Hekster, Y. A. (1987): Clinical pharmacokinetics of sulfonamides and their metabolites. Antibiot. Chemother. 37, 131-133.

Vree, T. B., Hekster, Y. A. and Tijhuis, M. W. (1985a): Metabolism of sulfonamides. Antibiot. Chemother. 34, 5-65.

Vree, T. B., Hekster, Y. A., Nouws, J. F. M. and Dorrestein, G. M. (1985b): Pharmacokinetics of sulfonamides in animals. Antibiot. Chemother. 34, 130-177.

Vree, T. B., Kolmer, E. W. J. B., Hekster, Y. A., Shimoda, M., Ono, M. and Miura, T. (1990): Pharmacokinetics, $\mathrm{N}^{1}$-glucuronidation, and $\mathrm{N}^{4}$-acetylation of sulfa-6-mono-methoxine in humans. Drug Metab. Dispos. 18, 852-858.

Vree, T. B., Vree, J. B., Kolmer, N. B., Hekster, Y. A., Shimoda, M., Nouws, J. F. M., Yoshioka, T. and Hoji, K. (1989a): Oxidation and O-dealkylation of sulphamonomethoxine by the turtle Pseudemys scripta elegans. Vet. Quart. 11, 186-190.

Vree, T. B., Vree, M. L., Beneken Kolmer, E. W. J., Hekster, Y. A., Shimoda, M., Nouws, J. F. M., Yoshioka, T. and Hoji, K. (1989b): Oxidation and O-dealkylation of sulphamonomethoxine by the snail Cepaea hortensis. Jpn. J. Vet. Sci. 51, 369-372.

Vree, T. B., Vree, J. B., Beneken Kolmer, Y. A., Hekster, Y. A., Shimoda, M., Nouws, J. F. M., Yoshioka, T. and Hoji, K. (1989c): O-demethylation and $\mathrm{N}_{4}$-acetylation of sulpha-dimethoxine by the turtle Pseudemys scripta elegans. Vet. Quart. 11, 138-143. 